\title{
Hyperkalemia in a patient with myasthenia gravis: case presentation
}

\author{
Mi-Chu Lin ${ }^{1}$, Ming-Hsien Tsai ${ }^{1,2}$, Jyh-Gang Leu ${ }^{1,2}$ and Yu-Wei Fang ${ }^{1,2^{*}}$
}

\begin{abstract}
Background: Myasthenia gravis (MG) is the most common disorder of neuromuscular transmission, and it is typified by fluctuating degrees and variable combinations of weakness in the ocular, bulbar, limb, and respiratory muscles. Under rare circumstances, MG can be accompanied by Addison's disease.

Case presentation: Here, we reported the case of a 57-year-old Chinese woman with MG. She experienced progressive muscle weakness for 1 week. MG with acute exacerbation was initially suspected. However, further biochemistry tests found mild hyperkalemia (5.6 mEq/L) and a lower renal potassium excretion rate. Consequently, low aldosterone action was highly suspected. Further findings included a suppressed cortisol level, a higher adrenocorticotropic hormone concentration, and 21-hydroxylase antibody positivity, supporting a diagnosis of primary adrenal insufficiency due to autoimmune adrenalitis.

Conclusion: We successfully demonstrated that adrenal insufficiency could be diagnosed, due to the presence of hyperkalemia. This case suggested a need for clinicians to consider the possible coincidence of adrenal insufficiency in a patient with MG and hyperkalemia. Early hormone supplementation should be begun.
\end{abstract}

Keywords: Autoimmune, Myasthenia gravis, Addison's disease, Hyperkalemia, Transtubular potassium gradient

\section{Background}

Myasthenia gravis (MG), an autoimmune disease caused by the blockade of nicotinic acetylcholine receptors in the junctions between the nerve and muscle by antibodies, is the most common disorder of neuromuscular transmission. More than 50\% of MG patients present with ptosis and diplopia, and approximately $15 \%$ present with bulbar symptoms, including fatigable chewing, dysphagia, and dysarthria [1]. MG has well-known links with various autoimmune diseases, such as Hashimoto's disease, Graves' disease, rheumatoid arthritis, systemic lupus erythematosus, and type 1 diabetes mellitus [2, 3]. However, case reports of coexistent MG and Addison's disease are rare.

In this study, we report a rare case of MG in a patient who presented with mild hyperkalemia, which finally led to a diagnosis of MG with primary adrenal insufficiency. We succeeded in diagnosing primary adrenal insufficiency

\footnotetext{
* Correspondence: m005916@gmail.com

${ }^{1}$ Division of Nephrology, Department of Internal Medicine, Shin Kong Wu Ho-Su Memorial Hospital, Taipei, Taiwan, Republic of China

${ }^{2}$ Fu-Jen Catholic University School of Medicine, Taipei, Taiwan, Republic of China
}

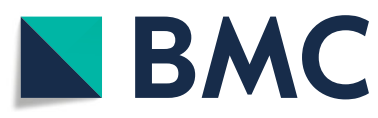

C The Author(s). 2019 Open Access This article is distributed under the terms of the Creative Commons Attribution 4.0 International License (http://creativecommons.org/licenses/by/4.0/), which permits unrestricted use, distribution, and

reproduction in any medium, provided you give appropriate credit to the original author(s) and the source, provide a link to the Creative Commons license, and indicate if changes were made. The Creative Commons Public Domain Dedication waiver (http://creativecommons.org/publicdomain/zero/1.0/) applies to the data made available in this article, unless otherwise stated.

\section{Case presentation}

A 57-year-old Chinese woman who was a carrier of the hepatitis $\mathrm{B}$ and $\mathrm{C}$ viruses and who had a 2-year history of MG was receiving treatment with oral Mestinon (pyridostigmine $120 \mathrm{mg}$ daily), which controlled her symptoms well (minimal bilateral ptosis, especially in the morning, and proximal muscle power of 4/5). The diagnosis of MG was verified by the presence of high levels of immunoglobulin $G$ antibodies directed against acetylcholine receptors $(54.23 \mathrm{nmol} / \mathrm{L})$. The stimulation single fiber electromyography recorded from orbicularis oculi muscle showed abnormal results (MCD: $180 \mathrm{~s}$ ), and repetitive nerve stimulation showed no decremental response. A chest computed-tomography (CT) scan showed a thymoma of about $3.2 \mathrm{~cm}$.

She presented with a 7-day history of poor appetite and progressive muscular weakness. Acute exacerbation of MG was initially considered by the neurologist but the muscle weakness did not improve in spite of an increased Mestinon dose to $360 \mathrm{mg}$ daily. She was referred 
to the nephrology department for further assessment because the laboratory data showed an electrolyte imbalance. Such symptoms such as nausea, vomiting, diarrhea, tarry stool, and lower extremity numbness were absent. There was no history of recent strenuous exercise or diuretic use.

On admission, physical examination revealed clear consciousness and symmetrical weakness of the lower extremities. The following laboratory findings were recorded: blood pressure, 116/64 $\mathrm{mmHg}$; heart rate, 82 beats/min; respiratory rate, 22 breaths/min; and body temperature, $36.8^{\circ} \mathrm{C}$. Moreover, a generalized skin pigmentation without long-term exposure to sunlight was noted. The remainder of the physical examination was unremarkable.

The results of the biochemical analyses are shown in Table 1 . The most prominent initial findings were mild hyperkalemia $(5.6 \mathrm{mEq} / \mathrm{L})$ and mild hyponatremia $(128$ $\mathrm{mEq} / \mathrm{L}$ ). Serial urinalysis during admission indicated a decreased $\mathrm{K}^{+}$excretion rate (transtubular potassium gradient $[$ TTKG $]=2.64$; urinary $\mathrm{K}^{+}$-creatinine ratio $=6.4$ $\mathrm{mmol} / \mathrm{mmol}$ ). Based on the findings of hyperkalemia with low urine potassium secretion, low aldosterone action was highly suspected. Subsequent hormone profiling revealed normal thyroid-stimulating hormone levels $(2.99 \mu \mathrm{g} / \mathrm{dL})$, an elevated renin concentration $(74.5 \mathrm{pg} / \mathrm{mL})$, and low aldosterone $(22.24 \mathrm{pg} / \mathrm{mL})$, and cortisol levels $(4.65 \mu \mathrm{g} / \mathrm{dL})$ (Table 1). Accordingly, adrenal insufficiency was diagnosed using the flow chart of hyperkalemia differentiation (Fig. 1). Moreover, the patient's elevated adrenocorticotropic hormone level $(84.4 \mathrm{pg} / \mathrm{mL})$ supported the diagnosis of primary adrenal insufficiency. Magnetic resonance imaging revealed bilateral shrinkage of the adrenal glands, confirming our diagnosis (Fig. 2). Because of the underlying disease of MG, autoimmune adrenalitis was highly suspected, and this was proven by 21 -hydroxylase antibody positivity. Thereafter, the final diagnosis was primary adrenal insufficiency due to autoimmune adrenalitis.

Fludrocortisone $(0.2 \mathrm{mg}$ daily) was prescribed as mineralocorticoid supplementation. The patient's serum electrolyte levels normalized, and her general weakness improved. Therefore, she was discharged with oral fludrocortisone $(0.2 \mathrm{mg}$ daily) treatment. At the 2-month follow-up, her serum $\mathrm{K}^{+}$concentration was $3.68 \mathrm{mEq} / \mathrm{L}$.

\section{Discussion}

Primary adrenocortical insufficiency (also termed Addison's disease) is caused by an impaired ability of the adrenal cortex to secrete glucocorticoids and mineralocorticoids, and secondary adrenal insufficiency is caused by hypothalamicpituitary axis suppression. Adrenocortical insufficiency must be presumptively considered in the presence of a broad spectrum of patient symptoms (weight loss, abdominal pain, nausea, vomiting, cutaneous hyperpigmentation),
Table 1 Laboratory data at admission

\begin{tabular}{|c|c|}
\hline Parameters (reference range) & Value \\
\hline \multicolumn{2}{|l|}{ Plasma } \\
\hline $\mathrm{PH}(7.35-7.45)$ & 7.40 \\
\hline Blood nitrogen (8-20 mg/dL) & 13 \\
\hline Creatinine $(0.5-1.5 \mathrm{mg} / \mathrm{dL})$ & 0.7 \\
\hline $\mathrm{Na}^{+}(133-145 \mathrm{mEq} / \mathrm{L})$ & $128^{\mathrm{a}}$ \\
\hline $\mathrm{K}^{+}(3.3-5.1 \mathrm{mEq} / \mathrm{L})$ & $5.6^{\mathrm{a}}$ \\
\hline $\mathrm{Cl}^{-}(96-108 \mathrm{mEq} / \mathrm{L})$ & 97 \\
\hline Calcium (8.4-10.2 mg/dL) & 9.4 \\
\hline Phosphate $(2.5-4.5 \mathrm{mg} / \mathrm{dL})$ & 3.7 \\
\hline Magnesium (1.5-2.5 mg/dL) & 2.2 \\
\hline Osmolality (278-305 mOsm/kg. H2O) & 265 \\
\hline 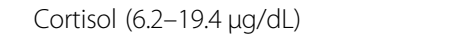 & 4.65 \\
\hline ACTH $(5-77$ pg/mL) & 84.4 \\
\hline Renin $(15-57 \mathrm{pg} / \mathrm{mL})$ & 74.5 \\
\hline Aldosterone (78-104 pg/mL) & 22.24 \\
\hline iPTH (15-65 pg/mL) & 66.79 \\
\hline TSH $(0.35-4.94 \mu \mathrm{g} / \mathrm{dL})$ & 2.99 \\
\hline ANA & $80+$ homogeneous \\
\hline Anti-ds DNA & $20 \times+$ \\
\hline \multicolumn{2}{|l|}{ Spot urine } \\
\hline $\mathrm{K}^{+}(\mathrm{mEq} / \mathrm{L})$ & 12 \\
\hline $\mathrm{Na}^{+}(\mathrm{mEq} / \mathrm{L})$ & 56 \\
\hline $\mathrm{Cl}^{-}(\mathrm{mEq} / \mathrm{L})$ & 44 \\
\hline Creatinine $(\mu \mathrm{g} / \mathrm{dl})$ & 21.1 \\
\hline Osmolality $\left(\mathrm{mOsm} / \mathrm{kg} \mathrm{H}_{2} \mathrm{O}\right)$ & 215 \\
\hline TTKG $\left(<9^{b}\right)$ & 2.64 \\
\hline $\mathrm{K}^{+} / \mathrm{Cr}(\mathrm{mmol} / \mathrm{mmol})\left(<15^{\mathrm{b}}\right)$ & 6.4 \\
\hline
\end{tabular}

Abbreviations: ACTH Adrenocorticotropic hormone, TSH thyrotropin, ANA antinuclear antibody, TTKG transtubular potassium gradient

alndicates abnormal values

${ }^{\mathrm{b}}$ Indicates reference range for normal renal response to hyperkalemia

changes in mood and personality, past medical history (diabetes, thyroid disease), and laboratory test data (hyperkalemia, hyponatremia, hypoglycemia, metabolic acidosis). If undetected or left untreated, adrenocortical insufficiency is associated with significant morbidity and mortality. Acute adrenal insufficiency is the result of critical life-threatening glucocorticoid and mineralocorticoid levels [7].

MG is a rare autoimmune disease caused by autoantibodies against the nicotinic acetylcholine receptor, the muscle specific tyrosine kinase or the low-density lipoprotein receptor-related protein 4 [8,9]. A thymoma is found in $15 \%$ of all MG patients. ThymomaMG may be associated with neuromyotonia, Sjogren's syndrome, or autoimmune hemolytic anemia [10]. MG is accompanied by increased risk for other autoimmune disorders [11]. 


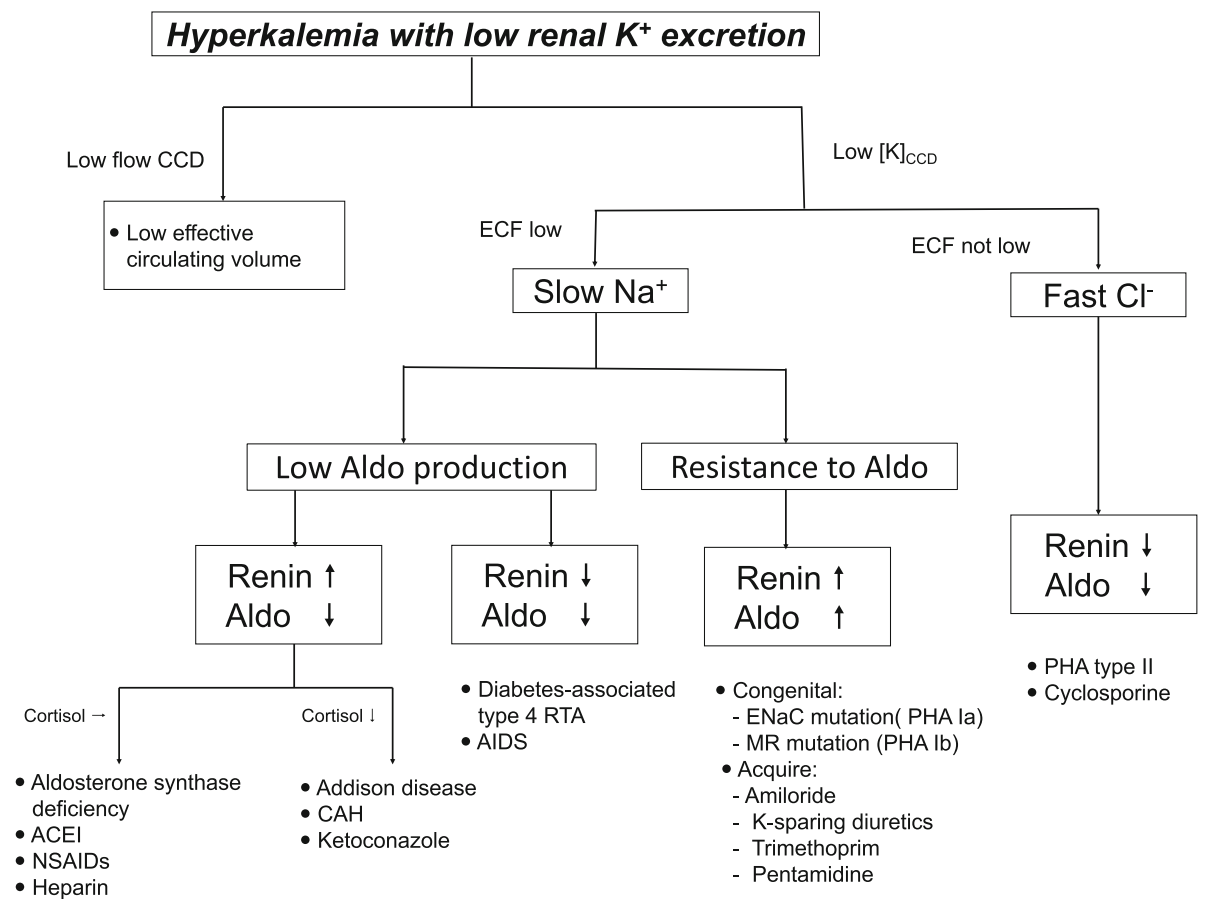

Fig. 1 Schematic illustration of the recommended diagnostic approach to hyperkalemia with low renal potassium secretion rate [4-6]. Abbreviations: CCD cortical collecting duct, ECF extracellular fluid, Aldo aldosterone, CAH congenital adrenal hyperplasia, ENaC epithelial sodium channel, NSAID nonsteroidal anti-inflammatory drugs, PHA pseudohypoaldosteronism, MR mineralocorticoid receptor

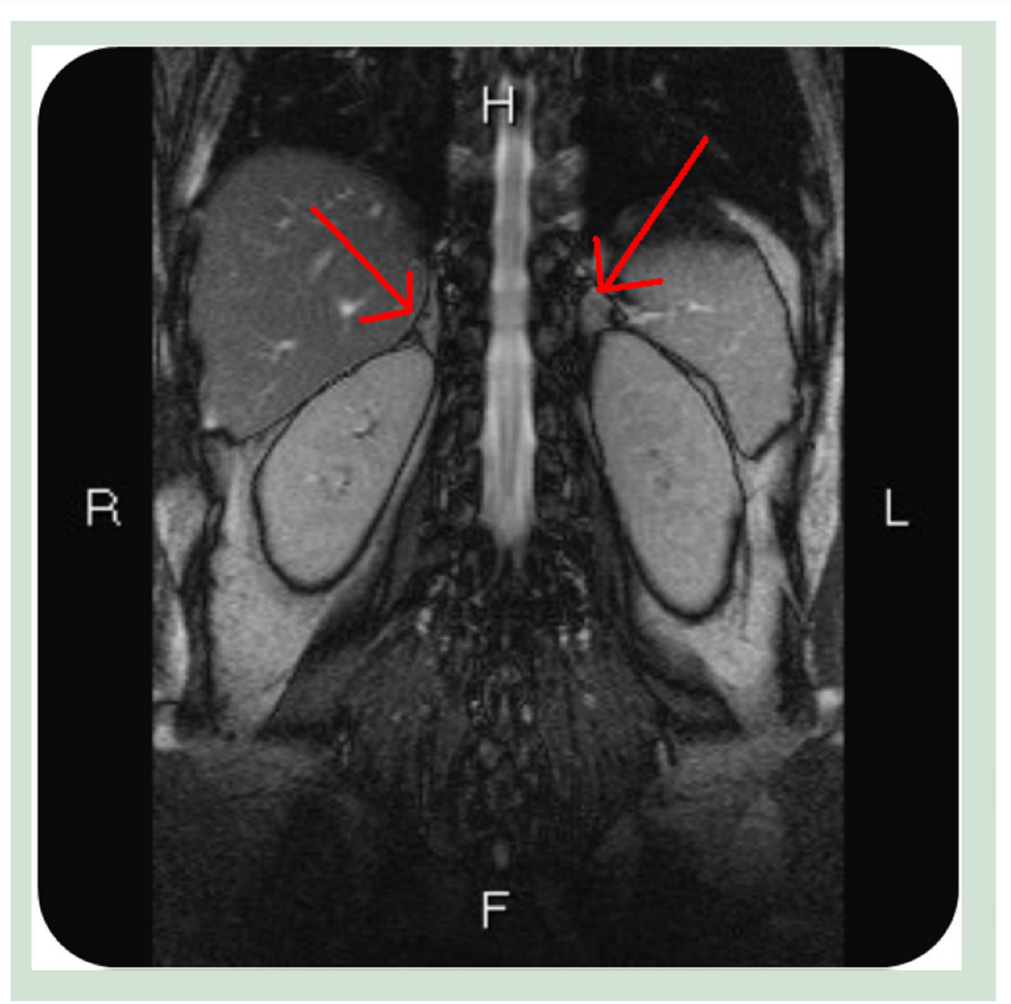

Fig. 2 Abdominal magnetic resonance imaging revealed the relatively small size of the bilateral adrenal gland (arrow) 
Table 2 Patients with association of myasthenia gravis and Addison's disease

\begin{tabular}{|c|c|c|c|c|c|c|c|c|c|}
\hline No & Studies & Year & Sex & $\begin{array}{l}\text { Age at MG } \\
\text { onset (year) }\end{array}$ & $\begin{array}{l}\text { Age at } A D \\
\text { onset (year) }\end{array}$ & Symptom & $\begin{array}{l}\text { Sodium } \\
\text { (mEq/L) }\end{array}$ & $\begin{array}{l}\text { Potassium } \\
(\mathrm{mEq} / \mathrm{L})\end{array}$ & PAS type 2 \\
\hline 1. & Bosh et al. [14] & 1977 & Female & 16 & 30 & Fatigue, weakness & 122 & 4.2 & Yes (Hypothyroidism) \\
\hline 2 & Dumas et al. [4] & 1985 & Female & 48 & 35 & Diplopia & NA & NA & No \\
\hline 3 & Dumas et al. [4] & 1985 & Male & 50 & 37 & Diplopia & NA & NA & No \\
\hline 4 & McAlpine et al. [15] & 1988 & Female & 17 & 47 & Nausea, vomiting & 99 & 4.9 & Yes (Hypothyroidism) \\
\hline 5 & Kane et al. [5] & 1950 & Male & 18 & 19 & Nausea, vomiting & 128 & 6.7 & No \\
\hline 6 & Okada et al. [6] & 1994 & Female & 38 & 53 & Nausea, diarrhea & 113 & 3.8 & No \\
\hline 7 & Seker et al. [17] & 2009 & Male & 32 & 32 & Weakness, vomiting & 144 & 3.8 & No \\
\hline 8 & Knno et al. [16] & 2009 & Female & 74 & 61 & Vomiting, headache & 137 & 3.9 & $\begin{array}{l}\text { Yes (autoimmune thyroid } \\
\text { disease) }\end{array}$ \\
\hline 9 & Our case & 2018 & Female & 55 & 57 & Fatigue, weakness & 128 & 5.6 & No \\
\hline
\end{tabular}

Abbreviations: $M G$ myasthenia gravis, $A D$ Addison's disease, $P A S$ polyglandular autoimmune syndrome, $N A$ not available

Polyglandular autoimmune syndrome (PAS) includes a wide spectrum of autoimmune disorders. PAS type 1, also termed autoimmune polyendocrinopathy-candidiasisectodermal dystrophy syndrome, is a rare autosomal recessive disorder of childhood [12]. Conversely, PAS type 2, which is far more prevalent than PAS type 1, occurs in adulthood. Primary adrenal insufficiency is the principal presentation of PAS type 2, and it is through autoimmune thyroid diseases (e.g., Hashimoto thyroiditis, Grave's disease) or type 1 diabetes mellitus [13]. In rare cases, PAS type 2 includes MG [14-16]. A coincidence of MG and Addison's disease has been reported [4-6, 17]. However, the present patient only presented with primary adrenal insufficiency and MG, indicating that a diagnosis of PAS type 2 is improper (Table 2).

Our patient had no history of other autoimmune diseases even though she presented with mild hyperkalemia (5.6 $\mathrm{mEq} / \mathrm{L})$ and mild hyponatremia $(128 \mathrm{mEq} / \mathrm{L})$. Physicians may consider these symptoms insignificant. However, we successfully diagnosed primary adrenal insufficiency due to immune adenitis early based on the presence of mild hyperkalemia, whereas in other studies, diagnoses of the condition have occurred at later stages, as indicated by the presence of severe hyponatremia (Table 2).

The three primary causes of hyperkalemia are increased $\mathrm{K}^{+}$intake, $\mathrm{K}^{+}$release from cells, and impaired renal $\mathrm{K}^{+}$ excretion. In our case, TTKG was low under the hyperkalemic status, indicating impaired renal $\mathrm{K}^{+}$excretion. A differential flow chart of hyperkalemia with low renal potassium secretion is shown in Fig. 2 [18-20]. First, impaired renal function and ineffective plasma volume should be eliminated as possibilities. Second, body fluid status should be elevated to distinguish the low sodium (low aldosterone action) and fast chloride types (normal aldosterone action). Finally, renin, aldosterone, and cortisol levels provide additional information regarding low aldosterone production and resistance to aldosterone action.

\section{Conclusion}

Autoimmune-related adrenal insufficiency should be considered in the differential diagnosis of patients with MG who present with mild hyperkalemia. Early diagnosis of adrenal insufficiency can lead to timely steroid therapy.

\section{Abbreviations}

ECF: extracellular fluid; MG: Myasthenia gravis (MG); PAS: Polyglandular autoimmune syndrome; TTKG: Transtubular potassium gradient

\section{Acknowledgments}

Not applicable.

\section{Authors' contributions}

$\mathrm{M}-\mathrm{CL}$ drafted the manuscript. Y-WF, M-HT, and J-GL led the conception and design, acquisition of data, and review of literature. Y-WF created the concept of the research paper and critically reviewed the manuscript. All authors read and approved the manuscript.

\section{Funding}

This work received no specific grant from any funding agency in the public, commercial, or not-for-profit sectors.

\section{Availability of data and materials}

Not applicable.

Ethics approval and consent to participate Not applicable.

\section{Consent for publication}

Written informed consent was obtained from the patient for the publication of this case report and any accompanying images.

\section{Competing interests}

The authors declare that they have no competing interests.

Received: 26 November 2018 Accepted: 11 July 2019

Published online: 26 July 2019

\section{References}

1. Silvestri NJ, Wolfe Gl. Myasthenia gravis. Semin Neurol. 2012;32(3):215-26.

2. Blanco Hernandez T, et al. Seronegative myasthenia gravis associated with other autoimmune diseases. Neurologia. 2009:24(6):424-8.

3. Thorlacius $\mathrm{S}$, et al. Associated disorders in myasthenia gravis: autoimmune diseases and their relation to thymectomy. Acta Neurol Scand. 1989:80(4): 290-5. 
4. Dumas $P$, et al. Myasthenia gravis associated with adrenocortical insufficiency. Report of two cases. J Neurol. 1985;232(6):354-6.

5. Kane CA, Weed L. Myasthenia gravis associated with adrenocortical insufficiency; report of a case with post-mortem findings and a review of the literature. N Engl J Med. 1950;243(24):939-44.

6. Okada T, et al. Myasthenia gravis associated with Addison's disease. Intern Med. 1994;33(11):686-8.

7. Neary N, Nieman L. Adrenal insufficiency: etiology, diagnosis and treatment. Curr Opin Endocrinol Diabetes Obes. 2010;17(3):217-23.

8. Zhang B, et al. Autoantibodies to lipoprotein-related protein 4 in patients with double-seronegative myasthenia gravis. Arch Neurol. 2012;69(4):445-51.

9. Gilhus NE. Autoimmune myasthenia gravis. Expert Rev Neurother. 2009;9(3): 351-8.

10. Nacu A, et al. Complicating autoimmune diseases in myasthenia gravis: a review. Autoimmunity. 2015:48(6):362-8.

11. Fang $F$, et al. The autoimmune spectrum of myasthenia gravis: a Swedish population-based study. J Intern Med. 2015;277(5):594-604

12. Fierabracci A. Type 1 diabetes in autoimmune Polyendocrinopathycandidiasis-ectodermal dystrophy syndrome (APECED): a "rare" manifestation in a "rare" disease. Int J Mol Sci. 2016;17(7).

13. Betterle C, et al. Type 2 polyglandular autoimmune disease (Schmidt's syndrome). J Pediatr Endocrinol Metab. 1996:9(Suppl 1):113-23.

14. Bosch EP, Reith PE, Granner DK. Myasthenia gravis and Schmidt syndrome. Neurology. 1977;27(12):1179-80.

15. McAlpine JK, Thomson JE. Myasthenia gravis and Schmidt syndrome. Postgrad Med J. 1988;64(756):787-8.

16. Konno $S$, et al. Autoimmune polyglandular syndrome type 2 with myasthenia gravis crisis. Neurologist. 2009;15(6):361-3.

17. Seker $\mathrm{M}$, et al. Myasthenia gravis and autoimmune Addison disease in a patient with thymoma. Clin Lung Cancer. 2009;10(5):367-70.

18. Eleftheriadis $\mathrm{T}$, et al. Differential diagnosis of hyperkalemia: an update to a complex problem. Hippokratia. 2012;16(4):294-302

19. Viera AJ, Wouk N. Potassium Disorders: Hypokalemia and Hyperkalemia. Am Fam Physician. 2015;92(6):487-95.

20. Lehnhardt A, Kemper MJ. Pathogenesis, diagnosis and management of hyperkalemia. Pediatr Nephrol. 2011;26(3):377-84.

\section{Publisher's Note}

Springer Nature remains neutral with regard to jurisdictional claims in published maps and institutional affiliations.

Ready to submit your research? Choose BMC and benefit from:

- fast, convenient online submission

- thorough peer review by experienced researchers in your field

- rapid publication on acceptance

- support for research data, including large and complex data types

- gold Open Access which fosters wider collaboration and increased citations

- maximum visibility for your research: over $100 \mathrm{M}$ website views per year

At $\mathrm{BMC}$, research is always in progress.

Learn more biomedcentral.com/submissions 